Version préliminaire de :

François Buton, Claire Lemercier \& Nicolas Mariot, "A Contextual

Analysis of Electoral Participation Sequences", in Philippe Blanchard, Felix Bühlmann \& Jacques-Antoine Gauthier (eds.),

Advances in Sequence Analysis: Theory, Method, Applications,

\title{
A Contextual Analysis of Electoral Participation Sequences
}

New York Heidelberg Dordrecht Londres, Springer, 2014, p. 191-212

François Buton, Claire Lemercier and Nicolas Mariot ${ }^{1}$

\begin{abstract}
This chapter presents an ongoing research project based on a seldom-used and particularly interesting source for the longitudinal, multilevel study of electoral participation: signature lists. We have been able to observe turnout in 44 ballots in one French polling station, between 1982 and 2007 (ca. 30,000 acts of turnout or abstention) and to link turnout data with various attributes of voters. We used sequence analysis to emphasize the correlation of participation patterns inside "electorate households" and to study the effect on turnout of the individual position in these households. This chapter discusses the ways in which this type of data and sequence methods makes it possible to take into account not only this social context of electoral participation, but also its temporal and political contexts. More generally, it exemplifies the uses of peculiar sequence data, with a very limited set of possible states but many dimensions to analyze.
\end{abstract}

\footnotetext{
F. Button

CNRS, Center for the Political Study of Latin Europe (CEPEL), Montpellier

C. Lemercier, corresponding author

CNRS, Center for the Sociology of Organizations (CSO), Paris.

e-mail: claire.lemercier@sciencespo.fr

Nicolas Mariot

CNRS, European Center for Sociology and Political Science (CESSP), Paris
}

\footnotetext{
${ }^{1}$ Acknowledgments: We thank all the participants in the LaCOSA conference for valuable suggestions and Richard Nice for an excellent editing of our English. This research has been funded by the French National Agency for Research, PAECE program.
} 


\section{Introduction}

This chapter presents the first steps in a collective research program, PAECE, that aims at qualifying mainstream models in electoral studies by considering electoral participation not merely as an individual act, but also as the product of social environments (CEPEL 2009). In order to observe such environments, small spaces of analysis have been chosen by each research team in PAECE, in the spirit of ecological analysis. In these French local contexts, it has been possible to use records of turnout in order to analyze behaviors, not discourses; this difference in sources is important, as abstention is under-reported in opinion polls and interviews (Braconnier and Dormagen 2007). We had of course no access to the contents of the vote, but we know whether registered voters participated in each election, thanks to signature lists. One of these teams, that of François Buton and Nicolas Mariot, especially built a longitudinal dataset: for one polling station, situated in a residential part of a town in the Paris region, it records 29,756 traces of acts of turnout or abstention, over three decades (1982-2008) and 44 ballots. It also includes limited but useful information on voters and especially on their living together in households.

Such a dataset requires some sort of sequence analysis. Of course, it is always possible to reduce turnout trajectories to one number by computing individual participation rates. We have done it and it has produced interesting results. However, patterns in the trajectories themselves also deserve to be described and interpreted. We have begun to do so in a paper that has been published in a mainstream journal in the field (Buton et al. 2012), despite or thanks to its methodological peculiarities. Interested readers should refer to this paper to learn more about the setting of the case study, which we will only briefly sum up here. Our first results are also presented there. They show an extremely high homogeneity of voting patterns inside what we call "electorate households" Registered voters who live together tend to vote or abstain at the exact same moments. Not taking into account this specific social dimension of participation thus leads to misinterpret it. This chapter provides a more methodological reading of the first stages of this research, those that led to the 2012 paper and those that happened afterward.

The firstsecond part presents the ways in which our research design allows us to contextualize the analysis of electoral participation. This design is replicable and in no way specific to France; we hope that it will be an inspiration for other researchers. The secondthird part sums up our published results on the correlation of participation behaviors inside households and the correlation between position in the household and participation. It shows why sequence analysis was essential in producing these results and how a slightly different, less standard modeling can help to better interpret them. The thirdfourth part opens an even more temporal question: do parents vote more when their children become potential voters? We show how visualizations help to tackle this question. The fifeurth and final part presents tentative results that differentiate ballots according to the type of election, hence introducing a third type of contextualization, after the synchronic household context and the diachronic context of individual voting trajectories.

\section{A Contextual Analysis}

Electoral studies generally belong to the realm of standard methods considering a "general linear reality", in the words of Abbott (2001). Information on voting 
behavior is gathered through large-scale surveys of representative samples of nonrelated voters. This behavior is explained by more or less standard attributes of voters, e.g. gender, age, occupation, religion. Voting is seen as a conscious decision, isolated from social contexts as well as isolated in time: even recent panel studies have rarely taken more than four ballots into account. Hence, turnout is often considered as the output of an individual, general tendency that can be, e.g., related to an interest in politics and correlated with variables such as age or education.

However, pioneering studies taking into account more than one ballot have abundantly shown that consistent participators and consistent abstainers were a minority (Lancelot 1968, Subileau and Toinet 1993). Our own data makes this point even clearer: if we concentrate on the 1,665 voters who were registered for at least three ballots, we only find $16 \%$ of consistent participators and $7 \%$ of consistent abstainers, most of the latter being registered eight times or less. Turnout thus has its patterns: trajectories are rarely plain, but they are not random either-hence the interest of exploring them.

We study them with hypotheses that are rather different from the standard model. We consider turnout as an institution, in the sense of something that individuals tend to take for granted, not to reflexively question: a sort of routine that is collectively performed, in which imitation, acting like other voters, plays an important role. Participation is not performed by everybody, for abstention happens; but it happens neither randomly nor necessarily as a product of an individual conscious decision. In some cases, abstention can also be a routine. This view of electoral participation calls for a contextualized study, in order to test the importance of various contexts: do voters act like voters close to them, especially in their own household (social context)? Do they act as they used to (temporal context)? Do they act like other voters at the same time, whatever the personal connection (political context)?

\subsection{Three Contexts of Turnout}

A very simple visualization of our trajectories, provided, like the rest of our analysis, by the $\mathrm{R}$ package TraMineR, clearly illustrates this point (Fig. 1; for R, see R Development Core Team 2013). Each line in this index-plot represents a voter, and lines are sorted according to their pairwise similarity, as defined by a distance that we will present below. The scarcity of consistent behaviors is visible. There are few completely black or green lines, describing consistent participators, and almost no completely orange or gray lines, denoting consistent abstention.

Many trajectories include large white patches: these are associated with ballots when the voter was not registered in this polling station. He could have been too young to vote (the minimum age is 18 in France) or deceased at that time, but most of these non-registrations are related to moves in space. In France, registration is automatically performed by the administration only for young people who turn 18; they are then registered at the polling station where they live. When a voter moves to another place, hence a different polling station, it is up to her to state it and make a new registration in her new domicile. If she has just moved to our polling station, her colored line begins at that time; if she has moved from our polling station to another, it ends.

Patterns in our trajectories are not only created by registration. Vertical orange/gray lines can be noticed in the dominant green/black landscape: while a majority of registered voters participated in most ballots, some are characterized by overwhelming abstention. In addition to these horizontal or vertical lines, a more 
subtle pattern is also apparent: there is more green in the lower-right corner, more orange in the upper-left one. It thus seems that those who became registered voters late in our period often tended to vote, contrary to those who were only registered in the early years. What is even more obvious, finally, is that much diversity remains to be described and explained, apart from these general patterns.

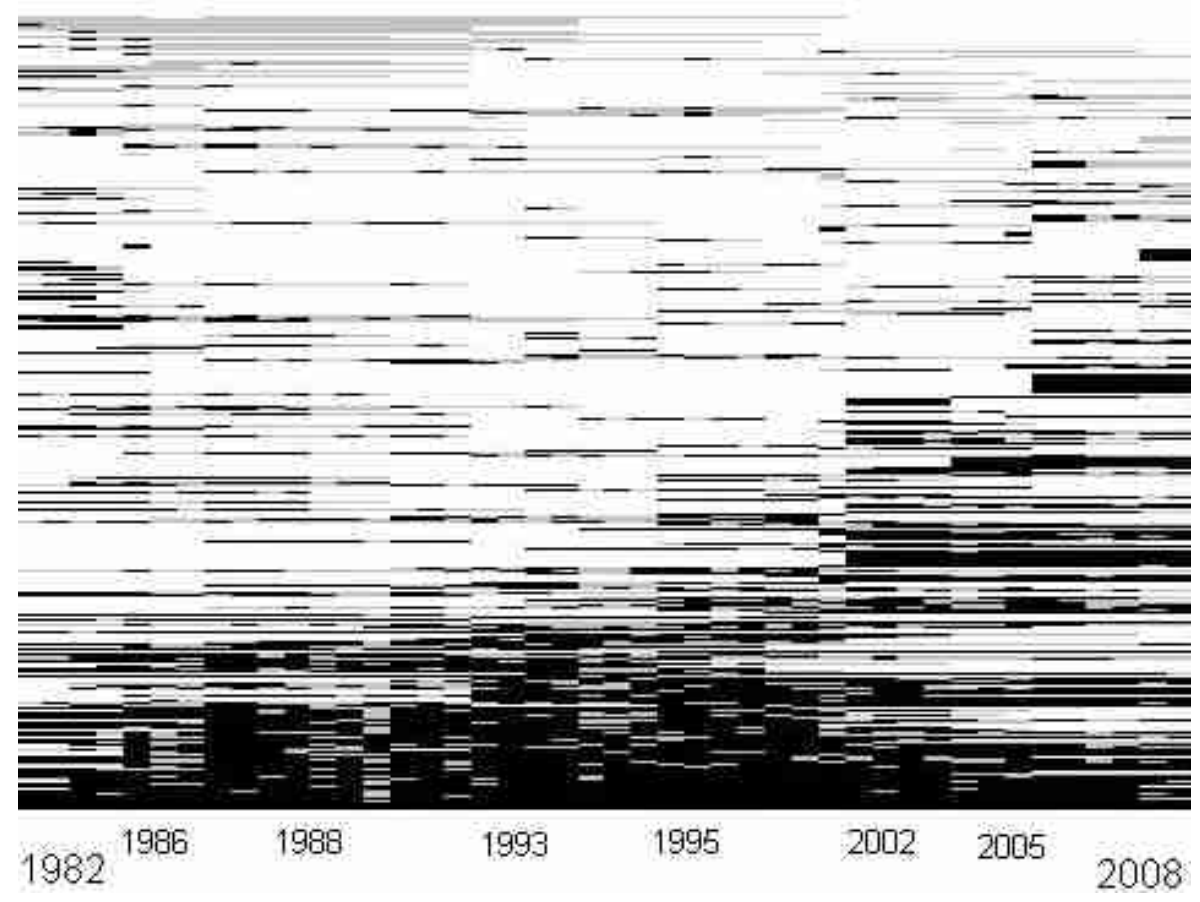

Fig. 1 A visualization of participation trajectories (index-plots). Sorting based on multi-dimensional scaling on the optimal matching distance defined below. Participation: Black/Green. Abstention: Gray/Orange. Not registered: White/White

The aim of our research is to provide such a description, which is not an easy task, if we want to take the timing and not only the aggregate number of acts into account. In addition, we will consider possible mechanisms that would help to make sense of this description. They relate to three types of contextualization: social, temporal and political. They will play a prominent role in the next parts of this chapter; let us briefly list them here.

First, voting does not appear as an individual decision, because people who live together tend to go, or not to go, to the polling station together. If we group the lines in Fig. 1 according to household, new, very sharp patterns appear that capture a large part of its diversity. It is our most important result, and taking timing into account allowed us to better assess it, as we will show in the secondthird part of this chapter.

Secondly, although consistent participators/abstainers are rare, it is reasonable to think of "participation careers" in which voters more or less consciously build on their previous actions, acting consistently in one way or another-even if consistency consists in regularly alternating between vote and abstention. In a side comment, Abbott (2005) clearly stated that in his view, standard electoral studies were wrong because they underestimated the fact that votes are mostly based on individual memories (he did not consider our two other types of context). Our dataset allows this sort of temporal contextualization, although we have not yet focused our investigations on it. The general idea, here, is to focus on the horizontal lines of Fig. 
1. Parts three and four of this chapter will show our first steps in this direction of a genuine longitudinal study.

Third, each moment in time, here each ballot, also can be considered as a specific context, in that the registered voters are more or less exposed to the same information from the mass media; to the same, narrow or wide, range of political parties, etc. It means that vertical lines in Fig. 1 are not to be ignored. Attributes of the ballots therefore should also be taken into account in our analysis-a dimension of context that we will briefly begin to address in part fourfive. While we have not yet brought all these dimensions together in a comprehensive description, let alone a model, our point is here to show that our research design, simple as it seems, allows us to tackle all of them.

\subsection{A Specific Research Design}

We chose this design because our background was quite distinct from that of specialists of electoral studies, which deserves a few comments. First, we learned quantitative methods in France, a country where specific, more descriptive and often more contextual methods than in the English-speaking world have been developed for applications in sociology and history and have become dominant in some fields-such as, for example, multiple correspondence analysis (Greenacre and Blasius 1994). Using formal methods in micro case studies that allow researchers to carefully build their own datasets, including non-standard variables, has been more routine there than elsewhere (see Lemercier and Zalc 2008 for a handbook and Mariot and Zalc 2010 for an example). Therefore, many French scholars have read Andrew Abbott's methodological work with enthusiasm (Demazière and Jouvenet forthcoming)-some of them are in fact co-authors of this very book. Secondly, we share ambiguous disciplinary allocations, somewhere between political science, sociology and history, which is related to the label "socio-histoire" (Buton and Mariot 2009). For present purposes, it translates into an interest in processes and configurations, in the spirit of Norbert Elias, and into the aim of dealing with social science questions by using "historical" sources, in the sense of traces, longitudinal data and data that is situated in time and space.

In this context, it was quite normal for the two of us who gathered data to input them ourselves from the source, during long days in the polling station. It allowed us to get a better, somewhat ethnographic knowledge both of the place and of the source, hence to devise better coding schemes and research questions: this type of data input can be considered as fieldwork. For example, one of the main drawbacks of our source is the lack of any direct indicator of education, wealth, occupation or social status. Personally knowing the place allowed us to decide on a coding of neighborhoods from addresses that offered reasonably defined clusters in terms of type of housing, hence indirect indications on social status. The specific history of the polling station also matters for our interpretation: initially a small village, it was included in the urban planning of the Paris region in the 1970s, and grew rapidly, with changing occupations, during our period. Finally, inputting very tedious data on turnout allows us to observe some of the standard and exceptional patterns in trajectories, which helped us to better mine a dataset that is at the same time very simple and very complicated. This research design, although produced, in our case, by a specific French academic socialization, could easily be adopted by other researchers. It would probably produce interesting results on electoral participation. More 
generally, it could benefit the methodology of sequence analysis by expanding its application to different types of data.

\subsection{Unusual Sequences}

Our dataset is indeed peculiar, as compared to what has until now been the bread and butter of sequence analysis: life-course and/or occupational trajectories, often gathered from large surveys that do not allow much re-coding of states or covariates. It is not only the political theme that creates this difference, but mainly the fact that our 1,799 individual trajectories are not statistically, or substantively, independent. On the contrary, the very purpose of our case study is to discuss whether similarities between trajectories can be related to ties between individuals, be it because of direct interactions in political discussions or because of shared exposure to the same microenvironment. As is classically the case in network analysis, in order to study such questions we have to forsake the advantages of large representative samples and turn to an ecological case study.

The problem of boundaries hence becomes complicated. Working on signature lists led us to concentrate on one polling station that provided us with a large enough number of trajectories. However, the perimeter of our polling station changed during the decades that we study. We chose to concentrate on a fixed perimeter in terms of addresses, considering all the voters who lived there and those alone. More importantly, as has already been seen in Fig. 1, people moved into and away from the part of town where our polling station was situated: only $9 \%$ of the population was registered during the whole period, while $10 \%$ was only registered for one ballot.

To deal with this issue, we had to accept a trade-off between two types of contextualization that we were interested in: on the one hand, that of voters among fellow voters registered in the same, small place (there were 500 to 800 simultaneously registered voters); on the other hand, that of voting acts among past and future voting acts by the same persons. Following voters from their first registration onwards, in their successive polling stations, would be completely impractical in terms of sources, as it would require us to look for records in many different places. Were it possible, it would certainly help us better understand how previous votes shape later votes and how this interacts with specific political contexts (prominence of the election in the media, number of candidates, etc.) and microenvironments (behavior of the parents, spouse, neighbors, etc.).

While our dataset is very local, historical and not very large, it is quite different from those built by Abbott and Hrycak (1990) in an early analysis of historical data, or by Blanchard (2012) in a study of multi-dimensional mobilization careers. In both cases, as in ours, the trajectories are those of named individuals who constitute the whole of a population; each line of the dataset is potentially interesting per se and in its relationships with others, and individuals are perceived as more than a collection of variables. We are not studying a representative sample of the French population. We are attempting a different sort of generalization. Our aim is to find interesting patterns in data on turnout and covariates and to hypothesize some of their generative mechanisms; it is these mechanisms that are offered as candidates for a role in other case studies.

This goal is probably shared with Abbott and Blanchard. However, as compared with their datasets, ours might appear ridiculously simple. We only study three possible states for each ballot: voting, not voting, not being registered. Although the third option creates methodological problems, coding, color-coding, etc. seem 
trivial in our case. In addition, our short list of variables was entirely built on the basis of the sex, name, maiden name, address, date and place of birth and date of first registration of the voter: this was all the information available in our source.

However, our ethnographic approach to data input and our intention of taking all the dimensions of contextualization seriously led us to consider these admittedly poor data as potentially rich in meaning (as advocated by Rosental 1999 for similar data on migration). For example, translating our data into a representation such as that in Fig. 1, a more or less standard operation in the non-standard field of sequence analysis, in fact involves at least two implicit decisions. First, any act of turnout is the same as the others (the same color, here). This is in fact not self-evident: voting when most of the population does not, for example, is admittedly a specific behavior-in the same way as working when most people do not (a problem which led Lesnard 2010 to devise a specific sequence dissimilarity metric). We had many discussions on how to take this point into account when computing individual participation rates; we finally chose flat rates for our 2012 paper and plain colors for our graphs, but we here present reflections on this topic in part fourfive. Secondly, time is treated in a peculiar way in our sequences, which are sequences of ballots. There were sometimes four ballots in an interval of eight days (two separate elections on the same days, with the first and second ballots for each), while we had an interval of three years without any ballot from 1989 to 1992 . We chose to consider only one act when two ballots happened on the same day, as almost all voters had consistent behaviors; but this leaves us with intervals ranging from one week to three years in calendar time, and with 10 separate ballots for 1988-89. Finally, we obviously do not know much on how voters considered their own "voting careers" and their timing, if they did at all. Our homogeneous time scale based on ballots, not years, is therefore a methodological choice in itself, to be questioned and possibly changed in future stages of this investigation.

\section{Households as a Context of Participation}

This simple way to consider participation trajectories as sequences of 44 successive states of participation, abstention or non-registration already led us to interesting results in terms of social contextualization. Had we not used sequence analysis ideas and software, these results would certainly have been less convincing. However, the fact that we published them in a mainstream journal has much to do with the recent evolution, led by TraMineR authors, toward including some forms of tests, thanks to permutations of data, in sequence analysis. These tests are useful even for a case study like ours which deals with non-independent trajectories-both as rhetorical devices that help to convince specialists in quantitative methods and, more importantly, as tools that proved fit to answer our main question: do people who live together also go and vote together?

In spite of the dominance of the standard models that we briefly sketched above, a few studies of voting and/or participation had already taken correlations among couples into account; one of them had even chosen households as a unit of observation, although with shorter observed trajectories (see e.g. Huckfeldt 1986, Verba et al. 2005, Braconnier and Dormagen 2007, and especially Johnston et al. 2005). We confirmed that this dimension should be taken into account in any analysis of turnout, as the magnitude of correlations in our case was very large. This magnitude could partly be due to the French schedule of elections, as they always happen on Sundays, when time spent together by household members is likely to be 
higher, on average, then on a standard working day. International comparisons would be required to test this hypothesis.

In order to assess the correlations among voting trajectories, we defined an "electorate household" as a group of registered voters who live together. Often, but not always, they are also married couples, or parents and children, or they share other kinship ties. The residential area that we study mostly includes detached houses, which helped us to define households on the basis of names, addresses and on-site observation. It should be noticed that "electorate households" are distinct from households in that we only consider registered voters. A registered woman with a foreign partner and young children, for example, would be counted as an "electorate household" of one. This captures ties of co-residence that empirically, in most cases, are also kinship ties. Ties with kin outside of the household, which arguably also play a role in electoral participation, could not be observed, and arguably were very few in the small space that we studied. What we are therefore able to assess is whether voters who are also coresident, and generally coresident kin, vote at the same moments. What we are interested in is the very collective character of this behavior. As in other studies of collective and especially family behavior, we are not able to determine if it is created by some sort of internal influence (from parents to children, or vice versa, etc.) or by exposure to a shared micro-environment (on this alternative, see e.g. Palloni et al. 2001).

\subsection{Correlations in Several Dimensions of Voting Trajectories}

On the basis of this definition, we found a correlation within households in terms of overall participation rates. We used ANOVA to show its significance. In addition, a multilevel regression that also included individual attributes such as the date of birth or that of registration demonstrated that the similarity within households had a significant, autonomous and very important effect on participation, representing a majority of the variance. However, this only proves that members of the same "electorate household" have similar aggregate tendencies to vote or not to vote, whatever the ballot.

We added to this result in two ways, by taking the sequential character of our data rather more seriously. First, we devised two alternative ways to measure participation, in addition to aggregate rates: a Change of Behavior Index and an optimal matching distance.

The Change of Behavior Index simply computed the number of changes from participation to abstention, and vice versa, as a proportion of the number of registrations, for each individual trajectory. This allows us to differentiate between two types of voters with similarly medium aggregate participation rates. The first type includes voters who turned from consistent participators to consistent abstainers, and vice versa. A proportion of them were in fact people who had moved away from the polling station, but neglected to change their registration. This phenomenon, called "misregistration", is common in France: especially when the new domicile is far away, voters who have not bothered to change their registration often do not make the trip back in order to vote, hence abstain. The second type is made up of voters who regularly alternate from vote to abstention, possibly according to the national or local character of elections, the available candidates, etc. Voters of the second type have a high Change of Behavior Index, contrary to those of the first type. This index also 
showed a very significant correlation within households, indicating similarities in the shape of participation careers, not only in aggregate participation rates.

In addition, we wanted to more directly demonstrate that people who lived together tended to participate at the exact same moments. This is essential for our institutional, routine interpretation of the act of voting: it is not simply some abstract tendency toward participation that is shared in an "electorate household", but the specific fact of participating at the same moment. This was done using a computation of dissimilarities between sequences based on an optimal matching distance. Had our data not included non-registrations, we would simply have counted the exact matches between sequences. The existence of this third state made optimal matching useful. We chose the lowest possible substitution costs between participation or abstention and registration (0.51) as compared to those between participation and abstention (1) in order to minimize the effect of non-registration on distances. In addition, we used very high indel costs (5), so that similar sequences were those where vote or abstention happened at the exact same moments-according to our research question. These choices of course do not totally prevent sequences from being considered close just because voters were registered at the same moments, but they minimize this effect as compared to those that were more substantively interesting for us.

This choice of costs allowed us to characterize each household by a level of internal variance between sequences and to compare such levels to that of the population as a whole. Pseudo ANOVA calculations implemented in TraMineR (Studer et al. 2011), although originally designed to test homogeneity of sequences in larger groups (such as women or the youngest), proved very useful in assessing the significance of similarity in temporal patterns of voting inside our 469 households that included more than one voter, and inside the 210 that included at least three. Changing scales to a visual inspection of the large households that showed an especially high or low internal variance helped us to better understand and describe our data. While tests added strength to our demonstration, such comings and goings between the population and examples, between numbers and visualizations, helped us to better grasp and describe our dataset.

\subsection{Participation and Position in the Household}

After having extended the study of correlations inside households to temporal patterns, we added a second dimension to the literature. Our data allowed us not only to define the perimeter of "electorate households" but also to assign a position in the household to each individual. After having tried more complicated coding schemes, we classified these positions as follows. "Couples" (27\% of individuals) are those who live as spouses (married or not) with another registered voter, but without any child registered as potential voter. "Children" $(21 \%)$ have at least one "parent" (22\%) present in their "electorate household", and vice versa. "Others" (4\%) live with at least one other registered voter, but do not fall into the previous categories. Finally, "isolated" voters $(26 \%)$ are the only registered voter in their household.

Our hypothesis was that households mattered not only because some sort of alignment of behaviors happened between their members, but also because they produced social roles that could influence participation, which would lead to differences within households. In our multilevel regression, which also included the household effect and other individual attributes, with the overall participation index as the dependent variable, position in the household indeed proved significant, with a hierarchy from "isolated" (who participated less) to "others", "children", "couples", 
and "parents" (who participated more). This effect is not that of age, as some "children" were older than "couples" and as the date of birth was also included as a covariate. It hints at a specific type of social integration that seems to affect turnout: not the existence of social or family ties per se, but that of ties with other registered voters of the same polling station.

While we did not publish it previously, both because of a lack of space and of the non-standard character of the method, we also tried to test the effect of position in the household, along with that of other individual covariates, on the exact timing of participation. To do this, we used the dissimilarity tree method implemented in TraMineR (Studer el al. 2011), that produced Fig. 2 and 3. This method performs a tree structured discrepancy analysis of objects that are described by their pairwise dissimilarities: here, participation trajectories described by their optimal matching distances. The procedure iteratively splits the data. At each step, it selects the variable and split that explains the biggest part of the discrepancy, i.e. the split for which we get the highest pseudo $\mathrm{R}^{2}$ in TraMineR's pseudo ANOVA procedure. The significance of the retained split is assessed through a permutation test. This method accommodates qualitative as well as quantitative variables; in each case, the algorithm decides on the best possible way to split the observed values into two groups. It is a generalization to sequences of the induction tree method of Breiman et al. (1984).

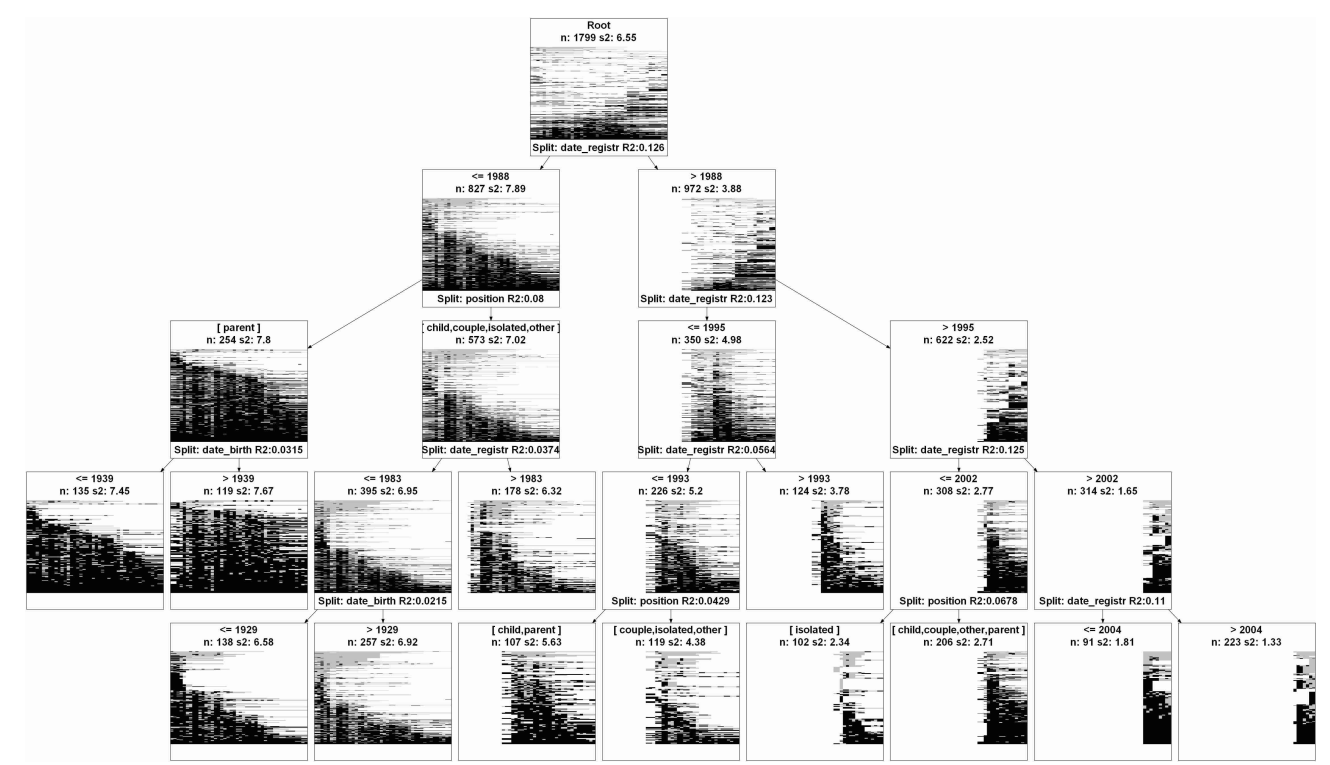

Fig. 2 Tree diagram based on an optimal matching distance-index-plots. Covariates that were included but do not show up in the results: sex, place of birth, neighborhood, and distance from address to the polling station (as in the multilevel regression included in Buton et al. 2012). Color code: Participation: Black/Green. Abstention: Gray/Orange. Not registered: White/White 


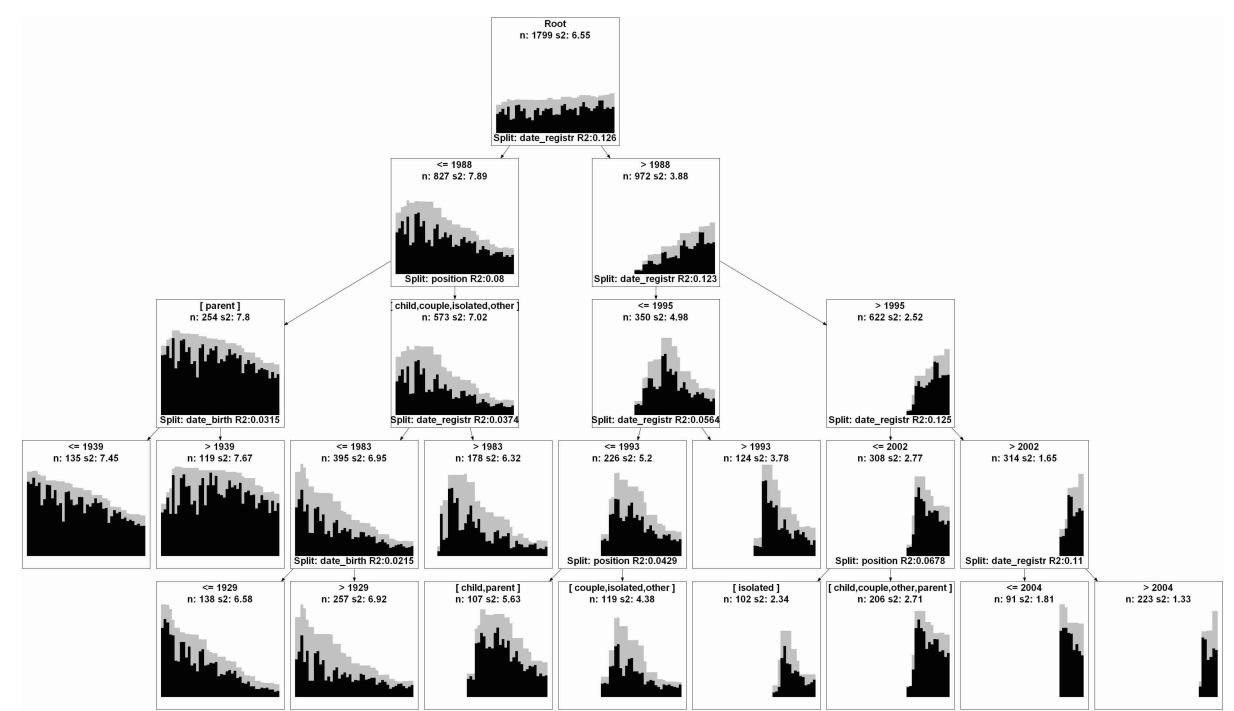

Fig. 3 Tree diagram based on an optimal matching distance-transversal distributions. Legend: see Fig. 2 .

This method has important limits in our case. First, due to the large number of different households, it is not possible to use multilevel modeling, including homogeneity inside each household along with individual covariates, while we have shown that it was an important dimension in our data. What we model here is thus something like a residual: what happens apart from this homogeneity. Secondly, what drives the model is the search for groups that have the lowest possible internal variance, in terms of distance between sequences as defined by optimal matching; despite our choice of costs, it is mostly in terms of date of registration, on the one hand, and of overall level of participation, on the other hand, that these groups appear quite visibly homogeneous. However, we can be confident that if something important sets them apart in terms of exact timing of turnout, it should be taken into account in the diagram.

This being said, this analysis is helpful to better understand our data in several ways. First, as compared to regression coefficients, the visualization helps to assess the magnitude of each variable and especially not to overestimate the homogeneity of behaviors among individuals that are similar according to a few significant covariates. For example, the 254 "parents" who registered before or in 1988 are quickly singled out by the model; but the internal variance in this group is higher than that of the total population (due to the fact that generally they were registered for a long time), and visual inspection reminds us of differences among them. Secondly, while the prominent part played by the date of registration in this model is admittedly partly due to the effect of non-registration on distances, what is not trivial is the way in which the procedure defined classes of dates, with significant breaks in 1988, then 1995, then 1993 and 2002. It is interesting to use such an inductive way to build classes, rather than using arbitrary thresholds; the same is true for dates of birth. Thirdly and more importantly, what a tree diagram does and a regression does not do is consider and put forward interactions among variables, not the independent action of those same variables. This is very much in the spirit of Abbott and of French methodologies, and we consider it an important complement to our regression.

As regards position in the household, the tree diagram very much validates its significance. It is the only covariate that appears in this model along with the date of registration and that of birth: the small effects of the place of birth and distance from 
the polling station that we found in the regression on overall participation rates do not show up in this model on the exact patterns of participation. Trajectories differ primarily according to the date of first registration, before or after 1988, which first splits the tree into two branches. For the early registrations, the difference between "parents" and all the other positions in the household causes the second significant split. For the later cohorts, it is still the date of registration that is most discriminating, with successive splits. However, position in the household also appears significant in those right-hand branches of the tree, except for voters who were only registered after 2002. Although its significance is higher for voters who were registered in 1988 or before, it is present almost everywhere.

While our regression showed a hierarchy of positions in terms of participation, the tree diagram adds that this hierarchy also applies to the duration of registration: "parents" tend both to be registered for a longer time and to vote more than the others and especially than the "isolated". Social integration in "electorate households", local integration in terms of registration (being registered, and not moving away) and electoral participation are strongly correlated. Finally, there are slight differences between branches of the tree in terms of which positions exactly are different from the others, as regards exact participation patterns. This is food for thought for our future investigations, for example as regards the difference between the "isolated" and all members of "electorate households": this difference is very strong for registrations happening between 1996 and 2002, but not for the other groups. Conversely, it is "parents" that are singled out in the first registration cohort. However, these small differences remain roughly consistent with our continuum of positions, from "isolated" to "parents". This intriguing effect of social integration thus deserves further investigation.

\section{Getting more Sequential: From Couples to Parents}

We present here a very preliminary investigation in this respect. It begins with a critical return to our coding scheme for positions in the "electorate households". Our definition of households and positions is static: each individual trajectory is related, in our database, to a given household, which is deemed to have, for example, four members; and each individual is assigned a position, e.g. that of "parent". However, in the simple case of a couple with two children who became voters during our period of observation, the number of voters in the household in fact increased from two to three, then four, while the "couple" became "parents". However convenient for a first step of analysis, it is thus somewhat odd to classify trajectories according to static labels.

In the case of positions in the households, there is a more substantive reason to take this matter seriously. How come that "parents" vote more than "couples"? "Couples" may or may not have children; what differentiates them from "parents", in our coding scheme, is that the children of "parents" are also registered voters in the same polling station. Why would this lead to higher participation? Do parents want or feel compelled to set an example by voting more, once their children are also registered? Or do "parents" participate more just because this position happens to be correlated with other variables, without having any specific causal effect? We have no final answer to this question, which will of course also require comparisons with other case studies and a more qualitative inquiry. Yet we can begin to tackle it, thanks to our database and a few visualizations. 
What can we learn by observing those "couples" who become "parents" in our dataset? Before talking about the "effect" of a "variable", it is important to observe the individuals who experienced a change in the modality of this variable (Blossfeld and Rohwer 2002). Here, while it rapidly leads us to manipulate small sub-samples, it provides food for thought and future testing. Let us consider the sub-sample of 120 "children" in our database who came to be registered after our first date of observation, along with their 215 parents. In fact, we only considered the first child in each household who was registered: the one who caused his parents to become "parents" in our coding scheme. We also excluded children who did not have at least one parent who was registered before them. Let us, in a first stage of investigation, ignore the fact that among these 215 parents, some are part of the same couple.

What we did was simply to align an index-plot not on calendar time, but on the date of an external event: the first ballot when a child of the individual was registered in the polling station. This apparently simple representation required the use of the piece of code devised by Denis Colombi and Simon Paye (see their chapter in this volume on aligning sequences on events). Figures 4 and 5 therefore have a quite different timeline from the other figures in this chapter: reading them requires some concentration, but this unusual representation offers new insights. Each line represents the trajectory of a parent. The ballot in the center of the figure, that between two close vertical lines (white lines in the black and white figure, bold lines in the color version), is the ballot when a child of the parent was first registered. According to our coding scheme, it is the time when a "couple" became "parents". This time occurred in various years: there is a calendar time scale for each line, as the sequence begins in 1982 and ends in 2008, but no common calendar time scale for the whole graph. Its scale is organized around the first ballot of the child, with "first ballot minus one, minus two, etc." on the left half and "first ballot plus one, plus two, etc." on the right half. The two additional vertical lines (black lines in the black and white version, thin lines in the color version) define the seven ballots before and after the first registration of the child.

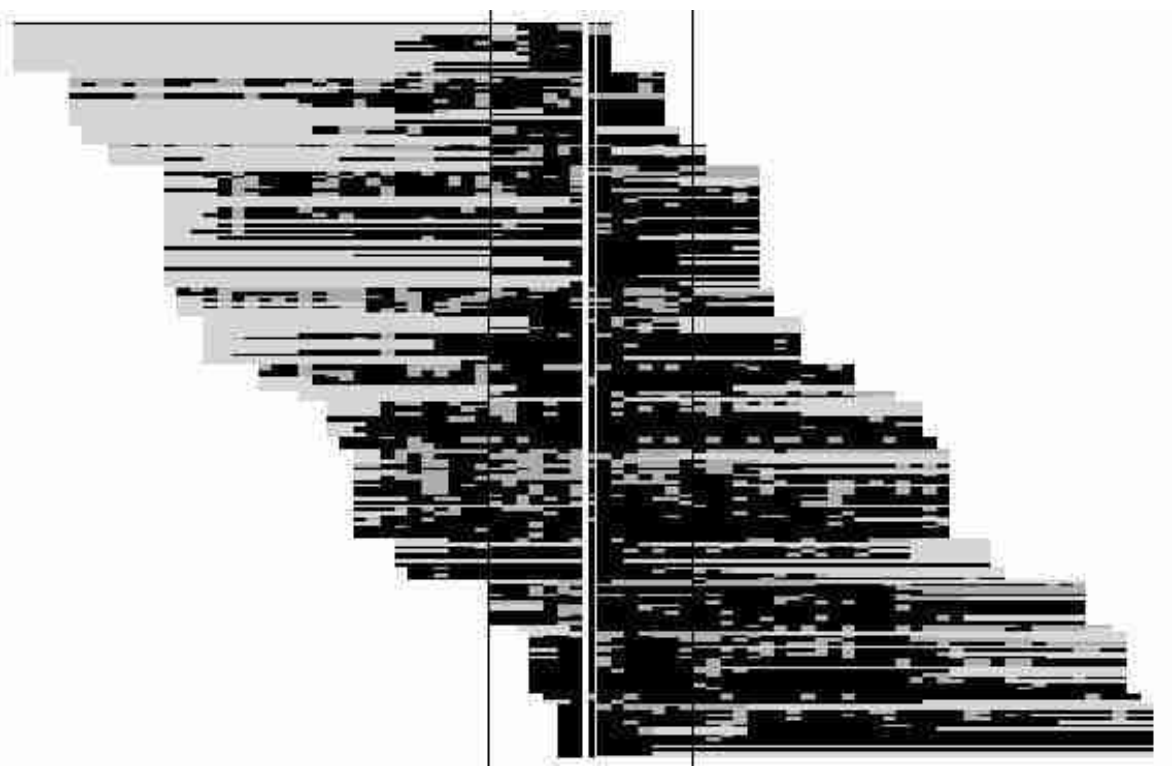

Fig. 4 Participation patterns of "parents" before and after the first registration of a child. Trajectories sorted according to registration date of the parent. Participation: Black/Green. Abstention: Dark Gray/Orange. Not registered: Light Gray/Gray 
No clear pattern emerges from Fig. 4, which is in itself a result: our event is not a turning point; it apparently does not have any lasting effect on trajectories. Its one noteworthy impact is transient: for the precise ballot when their first child becomes a registered voter, parents tend to vote, whatever their usual behavior. $100 \%$ of the few who were themselves not registered for the previous ballot participated; $94 \%$ of those who had participated did the same, as well as $71 \%$ of those who had abstained. The idea of setting a good example, as a kind of strategy of socialization into the voters' world, would thus apply. In our institutional understanding of participation, it would mean that, at a fairly macro level, the thing to do is to vote for the first ballot of your child. However, what is even more important is that this only holds true for one ballot: no difference is to be found in mean participation rates between all ballots before and after the event, or between the seven ballots directly before and directly after. Alternatively, it is possible that many children only registered when they and their parents intended to vote for the next ballot-when they were, in one way or another, especially interested in it. Empirically, ages of registration are far from always aligned on the minimum age of 18; they are often much higher. In any case, something interesting happens at the level of households, not only for children but also for parents, at this time when our "couples" become "parents"; but this effect does not seem to be enduring. It cannot explain the general difference in participation between "couples" and "parents".

However, careful visual exploration and successive sortings of our small subsample led us to complementary results. We were puzzled by the fact that participation decreased almost as often as increased when "couples" became "parents". The longitudinal study of change seemed to directly contradict our results based on static labels, thus questioning the very category of "parents": did they in fact vote more because this label was correlated with some other, hidden but more important variable? We therefore visualized differences between trajectories with an increase in overall mean participation after the event and those with a decrease, in order to better make sense of the latter (Fig. 5).
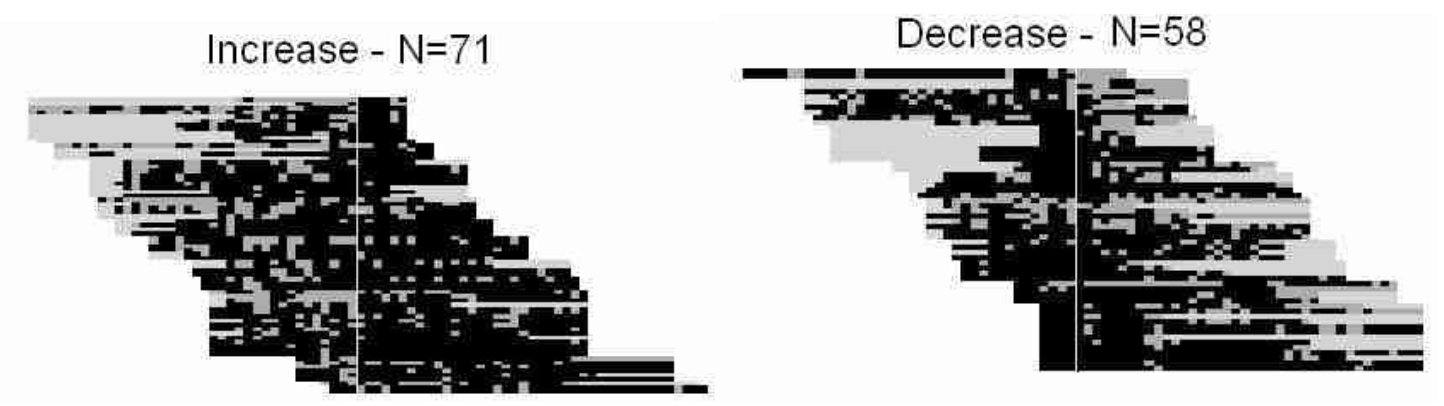

Fig. 5 Participation patterns of "parents" before and after the first registration of a child. Decrease vs. increase in overall participation rates. The only trajectories considered here are those that include at least four ballots before and after the event. Trajectories with equal rates before and after are also excluded. Color code: Participation: Black/Green. Abstention: Dark Gray/Orange. Not registered: Light Gray/Gray

Figure 5 gives a hint as to what happens in cases of decrease, as we see that many "parents" in this case eventually ceased to be registered at the polling station. We checked that it was not caused by their death-at least, their age was not especially high, or higher than in the other group. Spans of abstentions often happened just before this non-registration began. This hints at two possible, non-exclusive interpretations which will lead us to put new questions to our dataset. First, the 
decrease in participation is partly the effect of "misregistration", i.e. the abstention spans that appear when a voter has moved, but neglected to change registration. It is an arguably important and under-researched (see however Denni and Bon 1978, Braconnier and Dormagen 2007) dimension of abstention in systems with voluntary registration, like the French one, that we want to more generally take into account by measuring its frequency and discussing its association with various covariates.

Secondly, in other cases, an increased tendency toward abstention is directly followed by non-registration, without such spans. On the contrary, those "parents" whose participation increased after the event rarely ended up in a state of nonregistration. This could indicate that a strong tie to the place, in the sense of not leaving and not planning to leave, is correlated with the increased participation of "parents". It is all the more interesting as most "parents" with an increased participation rate had early dates of registration: they belong to the specific group that we had individualized in the left hand of the tree diagram (Fig. 2 and 3). These early registration cohorts, representing the original population of our zone-those who were born when it was a village, not the educated middle- or upper-class members who came later-generally had low participation rates, as discussed in Buton et al. 2012. These "parents" were an exception to this rule and even tended to participate more and more. Within this cohort, those who were firmly anchored in the place and whose children also became voters there seemed to have much more participatory behavior than others. This result per se is certainly specific for the place that we study, but it points to more general mechanisms as regards relationships between an enduring local anchoring at the level of the household and electoral participation. We will thus look for the same type of mechanisms, if not for the exact same results, in other case studies investigated in our research program.

Finally, another correlation with this decrease or increase in participation is worth mentioning. Small numbers call for caution in interpretation, but according to a rough classification of the neighborhoods in our zone into two groups, the more and the less wealthy, decreases happened more often in the latter group. A chi-square test is barely significant, but it is the only covariate that exhibits some sort of correlation. A provisional conclusion could be that the effect of "couples" becoming "parents" leading to an increase in participation only happens when the "parents" are wealthier and/or have a more longstanding relationship to the place. This is little more than a hypothesis, but it gives us directions for future qualitative and quantitative investigations. In addition to the two groups that we roughly defined in our first paper (villagers voting less and newcomers voting more), we are able to individualize a group of villagers who remained registered at the polling station during our period, who had children, and whose children became registered voters at their parents' address; they tend to live in the wealthiest neighborhoods and to participate more than others.

\section{A Vote is a Vote is a Vote?}

Finally, in the same exploratory spirit, we will present reflections on our third type of contextualization: political contextualization. How can we take into account types of elections and especially their prominence in the media, i.e. the political context? All the ballots were considered in the same way, represented with the same color, etc. in our previous analyses, be they the second ballot of the 2002 presidential election, with vibrant calls to participate in order to minimize the score of far-right Jean-Marie Le Pen, or the 1988 referendum on self-determination in the overseas territory of New 
Caledonia, with a national participation rate of less than $40 \%$ (on participation in France in diverse types of elections, see Héran 2004). Regarding the act of turnout as one and the same in all cases is debatable: different mechanisms could be at play in different types of elections, and social and temporal contexts could especially have different roles.

Our first idea in this respect was to differentiate between local and national elections. There are no consistent differences in overall turnout rates between the two categories, as the latter include, along with the presidential elections that are generally considered the most important events in French political life, referenda and European elections, which usually generate less turnout. However, reasons to participate in local and in national elections could be different. It is generally believed that the latter have more to do with parties and their programs and with national media, while the former leave more space to face-to-face relationships and local issues. We therefore wondered whether correlations inside households were as strong for each type of election. In addition, in our case study, we already found different patterns of participation across cohorts, both in terms of date of birth and date of registration. We interpreted them as proxies of more general social differences between inhabitants who had known the place as a village and middle- and upper-class baby-boomers who had settled later and had, on average, the highest participation rates. We could expect different behaviors in these two groups as regards local and national elections.

At the level of overall individual participation rates, there is some correlation between turnout for local and for national elections in our population; but, with an $\mathrm{R}^{2}$ of 0.55 , there are also many voters who regularly participated in national elections but not so much in local ones (the reverse case being much scarcer). Linear regressions with individual covariates as independent variables and the two separate participation indices as dependent variables show that the date of birth, place of birth and distance from the polling station had a significant effect only for local elections. Counterintuitively, it is in local elections that the difference in participation between newcomers and other is most significant, with newcomers voting more. It calls for a careful study of patterns of turnout for these elections, avoiding common sense equivalences between local anchorage and interest in local politics-as already shown by more qualitative studies (Girard 2011). Participation in national elections is much more difficult to model accurately than that in local elections-perhaps because it is more correlated with variables that we cannot observe, such as wealth, occupation, education or political commitment.

However, the effect that we are most interested in, that of the position in the household, is significant in both cases. In addition, ANOVA shows that correlations inside households are extremely strong and significant in both cases. This legitimizes the definition of trajectories that we have chosen in Buton et al. 2012 and in the first parts of this chapter. Considering participation trajectories as a whole, including a mix of local and national elections, is certainly a simplification and should not prevent us from studying, for example, the group of voters who participated more in national elections; however, the effects of cohorts of registration, household homogeneity and position in the household seem to have been at play whatever the type of election.

In order to assess this more precisely, we have just begun to analyze the specific case of presidential elections. Due to the prominence of these elections, it makes sense-from the point of view of the researcher, and possibly even if we think of more subjective "voting careers"-to extract our eight presidential ballots, for four elections, and to study them as specific trajectories (for a similar attempt at a macro level, see Bélanger et al. 2012). Figure 6 gives one possible representation of these 
quite simple but potentially interesting trajectories. It shows that there are few abstentions and even fewer constant abstentions for this sort of ballots. Voting only for the first or for the second ballot is not very common either. $3 \%$ to $7 \%$ of voters only participated in the first, $4 \%$ to (in 2002) $15 \%$ only in the second. It is an interesting pattern, as strategic discussions on voting often provide good reasons to do so, due to the too wide or too narrow political offer in each case. Abstention at only one of the two ballots of a presidential elections thus could be thought of as more "political", less "social" than other abstentions (on these concepts, see Subileau and Toinet 1993).

However, if this distinction makes sense, our results show that "political" decisions on turnout are a minority. For $77 \%$ of our population, presidential voting patterns only included a mix of non-registration and participation and, in a few cases, abstention at the two ballots. In such cases, looking for other contextual effects on participation, be they social or temporal, is pointless.

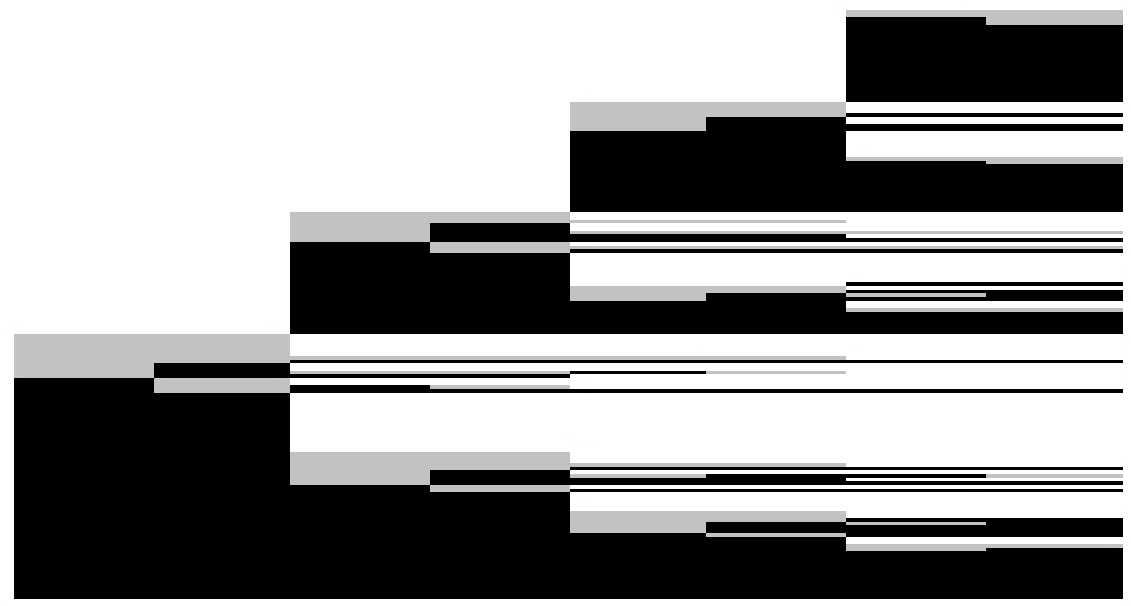

Fig. 6 Participation trajectories, presidential elections of 1988, 1995, 2002 and 2007. Trajectories are sorted according to the behavior at the first, second, etc., ballot (non-registration, then abstention, then participation). The individuals who were never registered for a presidential election are excluded $(\mathrm{N}=1,447)$. Color code: Participation: Black/Green. Abstention: Dark Gray/Orange. Not registered: White/White

We will however focus our further investigations on the other $23 \%$, those who sometimes changed behaviors between ballots. This rarely seemed to be a consistent behavior: the specific context of the moment of one election seems to have been more at play here than individual longstanding preferences or habits begun in previous elections. 88 voters participated only in the first ballot, only on one occasion, while 19 did it several times without doing the reverse or abstaining for both ballots; 169 voters participated only in the second ballot, only one time (half of them in 2002), while only six did it more consistently. If there is some sort of political strategy behind such behaviors, it is not independent of the specific context of each election. What seems much more promising is thus to look into household patterns in presidential election trajectories. A cursory look at them shows that some of the specific inter-ballot patterns are indeed found consistently in some households, where we could hypothesize the existence of shared, maybe even collectively discussed strategies; but there are also cases when voters in the same household have opposite behaviors for the same election. 
The presidential election is seen by many as the case when voters are most likely to make conscious choices according to political information provided beyond the borders of their household, due to the wide mass-media coverage. It is therefore a limiting case for us, as we are primarily interested in the weight of more local contexts. Our preliminary investigation does not point in the direction of decontextualized and/or purely "political" behaviors. For most voters, voting in a presidential election mostly appears as a taken-for-granted behavior; for smaller numbers, abstaining has the same status. One of our next steps will be to focus on household patterns in presidential election participation and to try to make sense of them, in order to better understand the minority of non-standard patterns.

\section{References}

Abbott, A. (2001). Time matters: On theory and method. Chicago: University of Chicago Press.

Abbott, A. (2005). The historicality of individuals. Social Science History, 29(1), $1-13$.

Abbott, A., \& Hrycak, A. (1990). Measuring resemblance in sequence data: An optimal matching analysis of musicians' careers. American Journal of Sociology, 96(1), 144-185.

Bélanger, É., Cautrès, B., Foucault, M., Lewis-Beck, M. S., \& Nadeau, R. (2012). Le vote des Français de Mitterrand à Sarkozy: 1988-1995-2002-2007. Paris: Presses de Sciences Po.

Blanchard, P. (2012). Analyse séquentielle et carrières militantes. Research Report. http://hal.archives-ouvertes.fr/hal-00476193. Accessed 13 June 2013.

Blossfeld, H.-P., \& Rohwer, G. (2002). Techniques of event history modeling: New approaches to causal analysis. Mahwah, NJ: Lawrence Erlbaum Associates.

Braconnier, C., \& Dormagen, J.-Y. (2007). La démocratie de l'abstention. Aux origines de la démobilisation électorale en milieu populaire. Paris: Gallimard.

Breiman, L., Friedman, J. H., Olshen, R. A., \& Stone, C. J. (1984). Classification and regression trees. New York: Chapman \& Hall.

Buton, P., Lemercier, C., \& Mariot, N. (2012). A contextual analysis of electoral participation sequences. Electoral Studies, 31(2), 434-447.

Buton, F., \& Mariot, N. (Eds.) (2009). Pratiques et méthodes de la socio-histoire. Paris: PUF.

CEPEL (2009). ANR "PEACE”. http://www.cepel.univ-montp1.fr/spip.php? article231\&lang=en. Accessed 13 June 2013.

Demazière, D., \& Jouvenet, M. (eds) (forthcoming). La sociologie d'Andrew Abbott. Paris: Éditions de l'EHESS.

Denni, B., \& Bon, F. (1978). Population électorale, population électorale potentielle, population totale dans la région Rhône-Alpes. Revue française de science politique, 28(6), 1055-1066.

Girard, V. (2011). Quelles catégories de classement pour l'analyse localisée de la représentation politique? Le cas des techniciens élus au sein d'un territoire industriel. Terrains \& Travaux, 19, 99-119.

Greenacre, M. J., \& Blasius, J. (1994). Correspondence analysis in the social sciences: Recent developments and applications. London; San Diego, CA: Academic Press. 
Héran, F. (2004). Voter toujours, parfois... ou jamais. In B. Cautrès \& N. Mayer (eds), Le nouveau désordre électoral. Les leçons du 21 avril 2002 (pp. 351-367). Paris: Presses de Sciences Po.

Huckfeldt, R. (1986). Politics in context. Assimilation and conflict in urban neighborhoods. New York: Agathon Press.

Johnston, R. J., Jones, K., Propper, C., Sarker, R., Burgess, S., \& Bolster, A. (2005). A missing level in the analyses of British voting behaviour: The household as context as shown by analyses of a 1992-1997 longitudinal survey. Electoral Studies, 24(2), 201-225.

Lancelot, A. (1968). L'abstentionnisme électoral en France. Paris: Armand Colin.

Lemercier, C., \& Zalc, C. (2008). Méthodes quantitatives pour l'historien. Paris: La Découverte.

Lesnard, L. (2010). Cost setting in optimal matching to uncover contemporaneous socio-temporal patterns. Sociological Methods \& Research, 38(3), 389-419.

Mariot, N., \& Zalc, C. (2010). Face à la persécution. 991 Juifs dans la guerre. Paris: Odile Jacob.

Palloni A., Massey D. S., Ceballos M., Espinosa K., \& Spittel, M. (2001). Social capital and international migration: A test using information on family networks. American Journal of Sociology, 106(5), 1262-1298.

R Development Core Team (2013). R: A language and environment for statistical computing. Vienna: R Foundation for Statistical Computing.

Rosental, P.-A. (1999). Les sentiers invisibles: espaces, familles et migrations dans la France du $19^{\circ}$ siècle. Paris: Éditions de l'EHESS.

Studer, M., Ritschard, G., Gabadinho, A., \& Müller, N. S. (2011). Discrepancy analysis of state sequences. Sociological Methods \& Research, 40(3), 471-510.

Subileau, F., \& Toinet, M.-F. (1993). Les chemins de l'abstention. Une comparaison franco-américaine. Paris: La Découverte.

Verba, S., Lehman Schlozman, K., \& Burns, N. (2005). Family ties. Understanding the intergenerational transmission of political participation. In A. S. Zuckerman (ed.), The social logics of politics. Personal networks as contexts for political behaviour (pp. 95-114). Philadelphia: Temple University Press. 